\title{
A Mutual Technique for Reconfiguration of Feeder Network by Optimal Locating and Sizing of Distribution Generator
}

\author{
Kothuri Ramakrishna1*, Basavaraja Banakara² \\ 1 Department of Electrical and Electronics Engineering, B. V. Raju Institute of Technology, Narsapur, Telangana, P.O.B. 502313, India \\ 2 Department of Electrical and Electronics Engineering, University of B.D.T. College of Engineering, Davanagere, Karnataka, \\ P.O.B. 577004, India \\ *Corresponding author, e-mail: ramakrishnakothuri004@gmail.com
}

Received: 10 May 2019, Accepted: 23 June 2019, Published online: 25 September 2019

\begin{abstract}
Common technique has been discussed in this paper for the reconfiguration of feeder network by optimal location and measuring of Distribution Generator (DG) in electrical power system. The consolidated execution of both Biography Based Optimization (BBO) and Particle Swarm Optimization (PSO) strategies are the curiosity of the proposed strategy. The optimization techniques are utilized for optimizing the optimum location and DG capacity for radial distribution network. The BBO algorithm requires radial distribution network voltage, real and reactive power for deciding the optimum location and capacity of the DG. Here, the input parameters of BBO are classified into sub parameters and permitted as the PSO algorithm optimization process. The PSO develops the sub solution with the assistance of sub parameters by issue synthesis. For identifying the optimum location and capacity of DG the BBO movement and mutation process is applied for the sub solution of PSO. At that point the proposed mutual technique is actualized in the MATLAB/simulink platform and by contrasting it with the BBO and PSO systems the effectiveness is scrutinized. The comparison results demonstrate the predominance of the proposed approach and affirm its capability to comprehend the issue.
\end{abstract}

Keywords

DG, BBO, PSO, voltage, real power, reactive power

\section{Introduction}

As of late, Distributed Generation (DG) have a tendency to participate an essential reason in Electrical Distribution Systems (EDS) because of natural troubles, charge of fuel vulnerabilities amongst of liberalization related with commercial centers energy [1]. The DGs have a tendency to be little-scale acquiring in devices between quantities of KWs for you to 100 MWs: micro, little, medium and tremendous DGs, alongside wasteful aspects which are adjusted at the load facilities to deteriorate power deficiencies [2]. Contrasted with tremendous primary power plants in view of non-renewable energy source, oil, alongside gas-terminated plants [3], the DGs assets for instance wind generators, PV, fuel cells, biomass, miniaturized scale generators, little hydroelectric plant, landfill gas, and so on, Borges and Falcão [4] get a lessened measure of assets expenditure alongside support maintenance and upkeep costs, the region is a great deal less demanding to get and have fewer ominous influence the surroundings [5]. The essential points of interest which are accessible from Distributed Generations have a tendency to be progression related with voltage stability \& profile, power loss lessening, superior system trustworthiness \& wellbeing alongside enhanced power quality (PQ) \& administration related with extra arrangements $[6,7]$. It's likewise exceptionally supportive in cutting down it yield price. In a separated tactic the DGs can be utilized or equal in a consolidated tactic. Subsequently, it can present in areas, where the central generation can be impracticable or much wherever you can discover insufficiencies in the real transmitting process $[8,9]$.

The DGs may help expected for hypothetically and financially, inside EDS in light of the fact that, the delay associated with transmission and distribution lines will upgrade wanders [10]. Then the DGs considerably affect the power development, voltage profile, voltage stability, continuity, short circuit level, and high quality associated with power intended for customers and energy buyers $[11,12]$. The real establishment associated in DGs might potentially best to network system method; anyway in the system requirements 
the violations is caused due to an abundance amount or even dimensions associated with DGs in operation [13]. That is the reason; the right sizes and position related with distributed turbines are fundamental proposed for most extreme preferred standpoint in the power system [14]. In the occasion Distributed Generation items have a tendency to consolidated the non-optimal spots, the power shortages increment, prompting raised power cost, toward the finish of your feeder voltage increment, inside a fault circumstance required supply unbalance, power high quality drop and reduction unwavering quality reaches [15]. A few other concerns related with the real DG establishment, which tends to be consonant shots, the call to embrace further developed command designs, and the likelihood of finding moderate power flows in power systems and the related dangers to help linemen prosperity [16]. The decision associated with optimum sizes and sitting is established on misfortune minimization, enhancement in the voltage profile, and abatement in the electrical power flows over the lines, bringing down consumption and strategy costs, and many others [17, 18]. Hence, the complex combinatorial promoting issue is the perfect offering of DGs in EDS [19]. The various techniques give within literary works are as follows: the classical optimizations, investigative technique, meta-heuristics, hybrid strategies, and so on [20].

The common strategy has been examined in the paper for area and the capacity of dispersion generator (DG) in electrical power system. The combined execution of both the Biography Based optimization (BBO) and Particle Swarm Optimization (PSO) techniques are the curiosity of the proposed strategy. The mentioned strategies are the techniques of optimization, which can be utilized for optimizing the optimum location and capacity of the DG in radial distribution network. The radial distribution network voltage, real and reactive power are the requirement of $\mathrm{BBO}$ algorithm, for determining the optimum location and capacity of the DG. Here, the input factors of BBO are characterized into sub factors and which are permitted for the process of PSO algorithm optimization. Thus, the PSO blend the issue and builds up the sub arrangement with the assistance of sub parameters. For the PSO sub arrangement, the BBO migration and mutation process is connected for recognizing the optimum location and DG capacity. The predetermined clarification of the proposed hybrid technique and UPFC power flow model are discussed in Section 3. Former to that, the present research works are presented in Section 2. The simulation results and the discussion are presented in Section 4. In Section 5 the paper is ends.

\section{Literature survey: A recent related work}

Kayal and Chanda [21] have suggested the multi-objective PSO dependent Wind Turbine Generation Unit (WTGU) notwithstanding photovoltaic (PV) array placement technique with regard to power loss reduction in addition to voltage balance progress regarding radial distribution system. The specific DG situating issue had been refined based on the WTGU notwithstanding PV range adequacy renditions. To examine the actual voltage adjust amount of assorted buses inside the system, a brand new Voltage Stability Factor (VSF) had been delivered. That could assess voltage balance infirmity in the total system furthermore. Wind in addition to solar DGs wound up handled in various productive in addition to reactive power mode (at diverse power factor) in addition to analyzed in the 12-bus, the 15-bus, and the 33-bus in addition to the 69-bus radial distribution system. From the investigated the impacts, it could determine the wind in addition to solar DG inside slacking p.f mode activated significantly greater progression in regards to voltage profile with respect to dispersion buses. Also, they revealed in which, the actual voltage magnitudes in the buses raised on the grounds that cut with respect to DG progressed. The specific VSF had been a powerful notwithstanding direct instrument contrasted with voltage balance files. From the prior mentioned conclusion, it had been mentioned the proposed approach performed more adequately, when compared to various other DG positioning tactics inside the system in regards to each power loss minimization in addition to voltage consistent enhancement in the technique.

Gopiya Naik et al. [22] get recommended an analytical technique intended for optimal site and measurement of DG as well as shunt capacitor intended for diminishing the overall authentic power failures. Pertaining to optimal site, any tenderness analysis process as well as intended for optimal measurement, the heuristic bend fitting strategies were being recommended. The actual proposed work ended up being embraced by means of assessment in 12-bus as well as IEEE 33-bus check submitting systems. From your received simulation benefits and comparability intended for distinct conditions, the suggested procedure can optimally distribute and also measuring the DG and addition capacitor blend in ways that reduced power failures together with good voltage profile and also diminish in the series loading in the power supply systems could possibly take place. So revealed the combination of DG and additionally capacitor could to a largely slow 
up the purchase besides expanding provide high quality as well as reliability then regular strategies.

Esmaili et al. [23] have offered a two point approach in view of dynamic programming lookup method to perfect designates and sizing the DGs which in turn efficiently utilizes Voltage Stability Margin (VSM) and reduces grid power cutbacks. Introductory, somewhat insecure chartering through voltage stableness perspective were established employing bifurcation evaluation because greatest places to run DGs. Variety of DGs has been thus selected of which system voltage profile has been introduced into the provided permissible voltage security confinements. Next, the overall perfect estimation associated with DGs has been established by utilizing the dynamic programming lookup procedure. It totally was exhibited of which, by means of taking into consideration DG reactive constraints, this built various voltage stableness bifurcations occurred, and additionally it affected the optimal location, measurement, and DGs number. This offered work has been examined on the basic 34-bus distribution test process.

Kansal et al. [24] have arranged PSO method for percentage associated with various types of DGs in regards to dynamic in addition to the reactive power compensation to limiting the electrical power distribution loss. The accompanying, the optimal power considers issue in addition has already been recognized to minimize the electrical power loss. The specific planned strategy has been examined on 33-bus in addition to 69-bus check methods. The outcomes from this PSO strategy have been weighed against this systematic methodology outputs. The specific arranged PSO strategy regarding optimal placement of several types of DGs not simply reduced this collection deficits but minimized this measurements connected with DGs with full satisfaction in the admissible voltage limitations.

Moradia et al. [25] have implemented an effective hybrid technique centered on Imperialist Competitive Algorithm (ICA) and in GA for maximum placement and DG alternatives size and the banks of capacitor concurrently with objectives in power loss reduction, expanding process voltage profile, expanding voltage stability index, load managing and transmission and distribution relief convenience of equally resources and the consumers. Initially, the ICA was utilized to discover area and size of the DGs and the capacitors. Hence, GA approach appeared to be utilized to create the most recent number of states and furthermore options inside the most research spots. This proposed work appeared to be connected on the IEEE 33 bus and also the 69 bus radial submission devices, addition to the impacts wound up contrasted and GA/PSO approach. Through the side by side comparisons, it exhibited the specific recommended approach seemed to be obviously better and also improved potential to locate the best alternatives.

Kashem et al. [26] reveal some sort of technique for that coordination of dispatchable and nondispatchable renewable distributed generation models for diminishing yearly quality failures. For the reason that technique, analytical words have been first offered to perceive the optimal dimensions and power issue of DG model together in each and every position for minimizing power failures. The words have been next adjusted to put renewable distributed generation models for minimizing yearly energy losses despite the fact that for the time- changing characteristics of demand and innovation. A combination of dispatchable distributed generation and nondispatchable distributed generation models seemed to be also they offered. The results exhibit of which dispatch able DG models or even a mixture of dispatch able and nondispatchable DG models can results exhibit decrease in yearly energy losses when contrasted with nondispatchable DG models.

Baran and $\mathrm{Wu}$ [27] get suggested an interactive fuzzy gratifying process, which will be based upon hybrid modified shuffled frog leaping algorithm, will settle the condition in the multi-objective optimal position and size related with DG models inside distribution network. Decreasing aggregate electric power losses, total electric power price and total pollutant emissions made have been the target abilities for the reason that difficulty. In like manner, the actual development in the voltage page has been believed to be a type of requirement all through discovering the ideal position. Inside the recommended process, the objective capabilities are designed together with fuzzy packages. This multi-objective issue has been changed directly into a mini-max snag that is treated with the prescribed progressive protocol. At last, the actual recommended protocol has been tested on the 69-bus submitting the testing technique based on specialized, cost-effective and environment safety criteria.

The reasonable capacitor undertaking, reconfiguration as well as DG section tend to be between the majority reputable techniques. Typically, good natural environment in the unaggressive distribution network, DG is which has an unaggressive operations procedure. Through this process, the capacity including DG seriously isn't considerable as opposed with the technique generation also as it might review the energy generated by centralized models. Just of late numerous logical tests happen to be taken 
together with expository and also misfortune affectability techniques for finding and additionally measure including DG. However, in these sorts of methods, the target functionality ended up being entire electrical power reductions that should end up plainly minimized by the analytical procedure and also without requiring the admittance matrix considering that the potential involving DG can be is dependent upon the reductions. Therefore, the optimization algorithm plays a large role for rigorous the capacity involving DG depending on electrical power reductions. Some of the algorithms have a tendency to be referred to as seeing that Genetic Algorithm (GA), Evolutionary Programming (EP), Simulated Annealing (SA), particle swam optimization (PSO), Cuckoo Search Algorithm (CSA) as well as and many others. In exact numerical optimization, several brand-new optimization tactics tend to be recommended to conquer the drawbacks of these conventional algorithms. Therefore, the importance involving conventional criteria can be changed with the invention involving brand-new looking for strategies. The specific prescribed technique to fix this entire problem can be temporarily reviewed inside the ensuing areas.

\section{Problem formulation}

At optimal location the DG units' is established which will prompt line loss diminishment, and enhanced the voltage dependability, the reliability and the security. The area of optimum and estimation of the DG is the optimization problem with nonlinear target work with the relating necessities like the power balance constraint, the voltage constraint and the constraints of DG and so on. In proposed technique the fundamental contribution is that, it should lessen the exact power loss, balance the load and deviation in voltage of the given radial distribution network at the peak load condition. Henceforth, it uses the multi-target capacity to decide the optimum location and sizing of the DG. Here, the multi- target function is logically formulated as the accompanying Eq. (1).

$$
\Phi=\operatorname{Min}\left\{f_{1}, f_{2}, f_{3}\right\}
$$

Where, $f_{1}, f_{2}$ and $f_{3}$ are the power loss, the voltage deviation and the load balancing respectively. Following are the mathematical equation of the multi-objective function.

\subsection{Power loss $\left(f_{1}\right)$}

During the peak loading conditions the distribution systems build insecurity, which leads to violations of constraint. The power loss is minimizing by obtained DG location and capacity and realizes the limits of the constraints. The exact loss of the required distribution system is evaluated by Eq. (2).

$$
f_{1}=P L^{D}=\sum_{i=1}^{N} \sum_{j=1}^{N}\left[\alpha_{i j}\left(P_{i} P_{j}+Q_{i} Q_{j}\right)+\beta_{i j}\left(Q_{i} P_{j}-P_{i} Q_{j}\right)\right]
$$

Where $\quad \alpha_{i j}=\frac{r_{i j}}{V_{i} V_{j}} \cos \left(\delta_{i}-\delta_{j}\right) \quad \beta_{i j}=\frac{r_{i j}}{V_{i} V_{j}} \sin \left(\delta_{i}-\delta_{j}\right)$, $P L^{D}$ is the distribution system exact loss; $r_{i j}$ is the resistance between bus $i$ and bus $j ; V_{i}$ and $V_{j}$ are the voltage magnitude of the buses $i$ and $j$ respectively; $\delta_{i}$ is the voltage angle at the bus $i ; \delta_{j}$ is the voltage angle at bus $j ; P_{i}$ and $Q_{i}$ active and reactive power injection at bus $i ; P_{j}$ and $Q_{j}$ is the active and reactive power injection at bus $j$. Section 2.1 persistents the voltage deviation.

\subsection{Voltage deviation $\left(f_{2}\right)$}

The essential factor in radial distribution network is a voltage profile management. At the point the voltage profile is changed, when DG is associated with a distribution network. It can be assessed at all of the buses in the radial distribution systems. Here, for upgrading the voltage stability, the perceived DG should limit the distinction between the normal bus voltage and the specified bus voltage. The voltage deviation equation is portrayed in the accompanying Eq. (3),

$f_{2}=\sum_{i=1}^{N}\left(\frac{V_{i}-V_{\text {spec }}}{V_{\text {spec }}}\right)$.

Where, $V_{\text {spec }}$ is the specified voltage; normally the required voltage is taken by 0.95 to 1.05 limit. The load balancing objective condition is characterized in the following Section 3.3.

\subsection{Load balancing $\left(f_{3}\right)$}

Here, the load balancing of lines is accompanying in Eq. (4).

$f_{3}=\sum_{i=1}^{N}\left(\frac{I_{i}}{I_{L}^{\text {avg }}}\right)$

Where, $I_{i}$ is current of branch $i$; this branch current should not transcend the thermal limit, i.e., $I_{i} \leq I_{i}^{\text {rated }}, I_{N}^{\text {avg }}$ is the total lines average current, which is resolved by the following relation in Eq. (5).

$I_{N}^{\text {avg }}=\sum_{L=1}^{N}\left(\frac{I_{L}}{N}\right)$

Where, $N$ is the total number of lines; the constraints subjected and the mathematical equations, which are elucidated in the Section 3.4. 


\subsection{Constraints}

\subsubsection{Power balance constraint}

The generated DG power is characterized by power balance constraint which is given in Eqs. (6) and (7).

$$
\begin{aligned}
& P_{D i}^{D}=P_{G i}^{D}-Y_{i j} \sum_{i=j=1}^{N} V_{i} V_{j} \cos \left(\delta_{i}-\delta_{j}-\theta_{i}\right) \\
& Q_{D i}^{D}=Q_{G i}^{D}-Y_{i j} \sum_{i=j=1}^{N} V_{i} V_{j} \sin \left(\delta_{i}-\delta_{j}-\theta_{i}\right)
\end{aligned}
$$

Where, $P_{G i}^{D}$ and $Q_{G i}^{D}$ are the generators power generations at bus $i ; Y_{i j}$ is the line admittance between $i$ and $j$; $\theta_{i}$ is phase angle of the bus $i ; P_{D i}^{D}$ and $Q_{D i}^{D}$ is the load demand at bus $j$; which is lies in the following limit $P_{D i}^{D(\min )} \leq P_{D i}^{D} \leq P_{D i}^{D(\max )}$ and $Q_{D i}^{D(\min )} \leq Q_{D i}^{D} \leq Q_{D i}^{D(\max )}$.

\subsubsection{Voltage constraint}

Within the prescriptive limits the voltage limits of each bus must lay, which are inclined in the accompanying Eq. (8).

$V^{\min } \leq V_{i} \leq V^{\max }$

Where, $V^{\text {min }}$ is the minimum voltage value and $V^{\max }$ is the maximum values of voltage at bus $i$; usually the bus voltage lies between $0.95 \leq V_{i} \leq 1.05 \mathrm{pu}$.

\subsubsection{DG constraint}

The allowable capacity for the buses is the DG constraint mainly essential and the comparing power factor of the DG. The capacity of the DG is portrayed in the accompanying condition in Eq. (9).

$\sum_{i \in N} \sqrt{\left(P_{i}^{D G}\right)^{2}+\left(Q_{i}^{D G}\right)^{2}} \leq \frac{1}{2} \sum_{i \in N} \sqrt{\left(P_{i}^{L}\right)^{2}+\left(Q_{i}^{L}\right)^{2}}$

$P F_{\min }^{D G} \leq P F_{i}^{D G} \leq P F_{\max }^{D G}$

Where, $P F_{\min }^{D G}$ is the minimum value of power factor and $P F_{\max }^{D G}$ is the maximum values of power factor at the DG bus $i$. The proposed technique utilizes the constraints to discover the location, which has greater need of genuine power loss sensitivity factor. Contingent on the loss function the corresponding capacity of DG has been distinguished and added to the specific area. In the Section 4 the short process about the assurance of DG location and capacity using the proposed method is portrayed.

\section{Proposed mutual technique for reconfiguration of feeder network by the optimum location and capacity of DG}

The proposed common technique has the consolidated operation of both the BBO algorithm and PSO algorithm. The predefined techniques are the optimization techniques, which are utilized for optimizing the optimum location and capacity of the DG for radial distribution network. The radial distribution network voltage, real and reactive power for the optimum location and capacity of the DG are the requirement of BBO algorithm. Here, the parameters in input are demonstrated hatred into sub parameters and permitted as the PSO algorithm. With the assistance of sub parameters the PSO synthesis the issue and enhance the sub solution.

For the sub solution of PSO the BBO relocation and change process is associated and identify the optimum location and capacity of DG. At that point the best solution is concluded from two system results. The steps to recognize the optimum location and capacity of DG for radial distribution network are depicted in the following.

\subsection{Steps to find the optimum location and capacity of $\mathrm{DG}$}

Step 1: Initialize the input parameters of BBO like radial distribution network bus voltage $\left(V_{i}\right)$, real and reactive power $\left(P_{i}\right.$ and $\left.Q_{i}\right)$ etc.

Step 2: Run the load flow in normal condition for the radial distribution network.

Step 3: Find the normal condition power loss using the Eq. (2) and the real power loss sensitivity factor is recognized using the Eq. (11) for all the buses. In descending order the bus loss sensitivity factor is arranged.

$$
R P_{l s f}=\frac{\Delta P L^{D}}{\Delta P_{i}}=2 \sum_{i=1}^{N}\left(\alpha_{i j} P_{j}-\beta_{i j} Q_{j}\right)
$$

Step 4: Using the multi-objective function Eq. (1), the BBO identifies the optimum location and capacity of DG.

Step 5: The input BBO parameters are categorized into sub parameters and then utilized as the PSO initialization. The PSO input parameters categorization is explained in the above Fig. 1.

Step 6: The " $N$ " number of initial populations is randomly generated by PSO. In this paper; the bus voltage of 


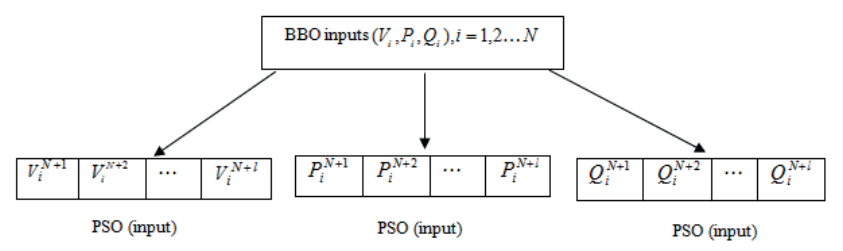

Fig. 1 PSO input parameters classification

radial distribution network is $\left(V_{i}\right)$, for initial population the real and reactive power $\left(P_{i}\right.$ and $\left.Q_{i}\right)$ is selected.

Step 7: The real power sensitivity factor in Eq. (11) is fined for every particle and in descending order the bus loss sensitivity factor are arranged. In each particle, the fitness has been evaluated by using the power loss, voltage deviation and load balancing equations.

Step 8: The particles are categorized into two groups Depends on evaluation of the fitness function, i.e., maximum and minimum fitness. As per the multi-objective function, the optimum location and capacity of DG is resolved, from this classification Eq. (1).

Step 9: For every single best particle, velocity and position is altered by using the Eqs. (12) and (13).

$$
\begin{aligned}
& \begin{array}{l}
v[]=v[]+c 1 * \operatorname{rand}(])(\operatorname{pbest}[]-\operatorname{present}[]) \\
+c 2 * \operatorname{rand}() *(\operatorname{gbest}[]-\operatorname{present}[])
\end{array} \\
& \text { present }[]=\operatorname{present}[]+v[]
\end{aligned}
$$

$v[$ ] is the velocity of particle, present [ ] is the current particle, pbest [ ] and gbest [ ] are best fitness value and best value from any particle in the population respectively, $\operatorname{rand}()$ is the random number between $(0,1)$ and learning factors are $c 1, c 2$.

Step 10: Again the multi-objective function are evaluate by using the updated particles.

Step 11: The iteration limit are checked, if it reaches the maximum number, go to or else the iteration number is boost and go back to the Step 7.

Step 12: Finalize the best solution by contrasting the PSO result with the $\mathrm{BBO}$ result.

Step 13: Finish the process.

The proposed mutual technique is prepared to give the best location and capacity of DG, Once the process is finished in radial distribution network. At that point the review of the proposed technique is portrayed in the above Fig. 2. The optimum location and capacity of DG assurance utilizing the PSO by using the BBO input parameter is explained in the Fig. 3.

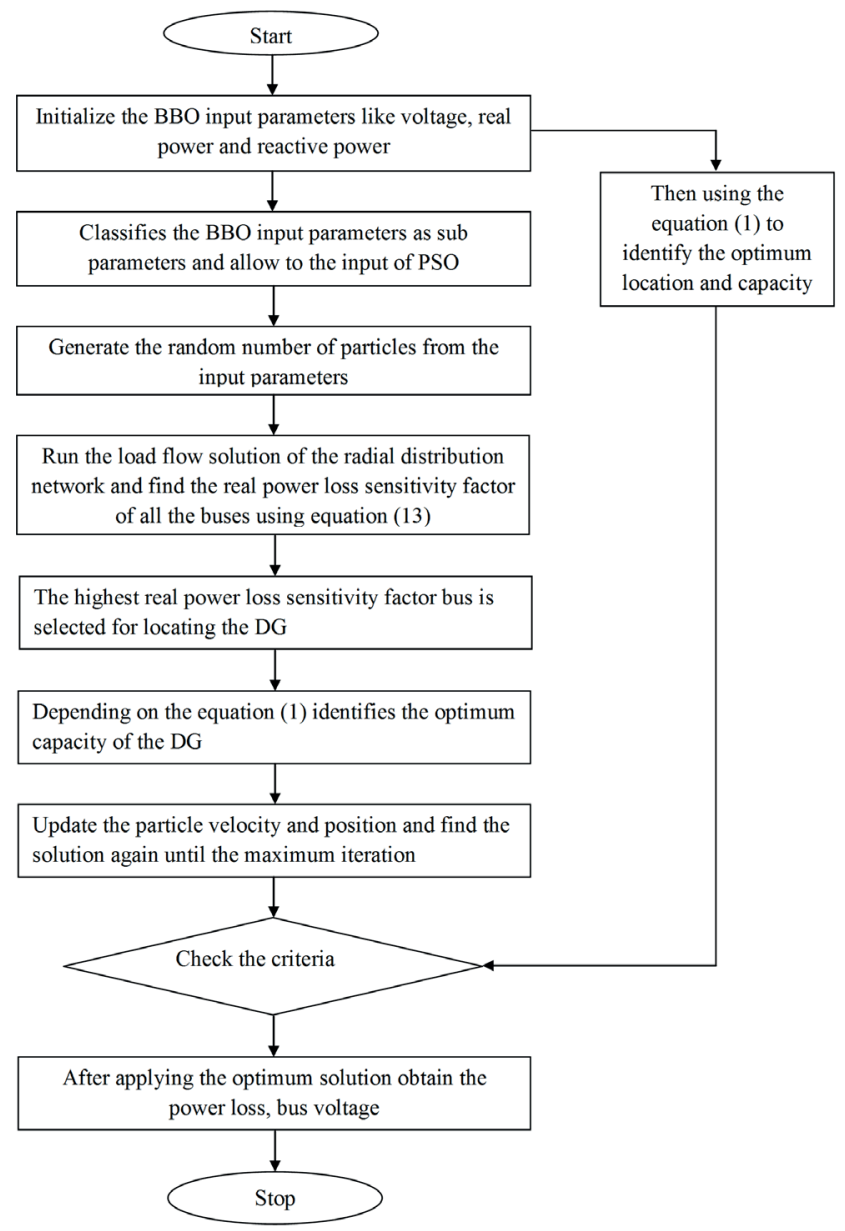

Fig. 2 Structure of the proposed mutual technique

At that point the proposed mutual technique is clarified under MATLAB stage through the IEEE standard benchmark system. The other techniques like BBO and PSO the tried outcomes are contrasted. The Section 4 describes the results of proposed mutual strategy and corresponding discussion.

\section{Results and discussions}

The proposed mutual technique is executed in MATLAB/ Simulink 7.10.0 (R2012a) platform, the 4GB RAM and Intel(R) core(TM) i5. The IEEE standard seat checks system like the 33 bus, which is utilized for the optimum location and DG sizing is scrutinize. Then the comparative analysis with the BBO and PSO technique is utilized for identifying the adequacy of the proposed method. Here, the objective functions are the power loss minimization, deviation in voltage and load balancing. Depending on the objective function the optimum location and DG capacity are fined by the proposed technique. By using the IEEE 33 radial 


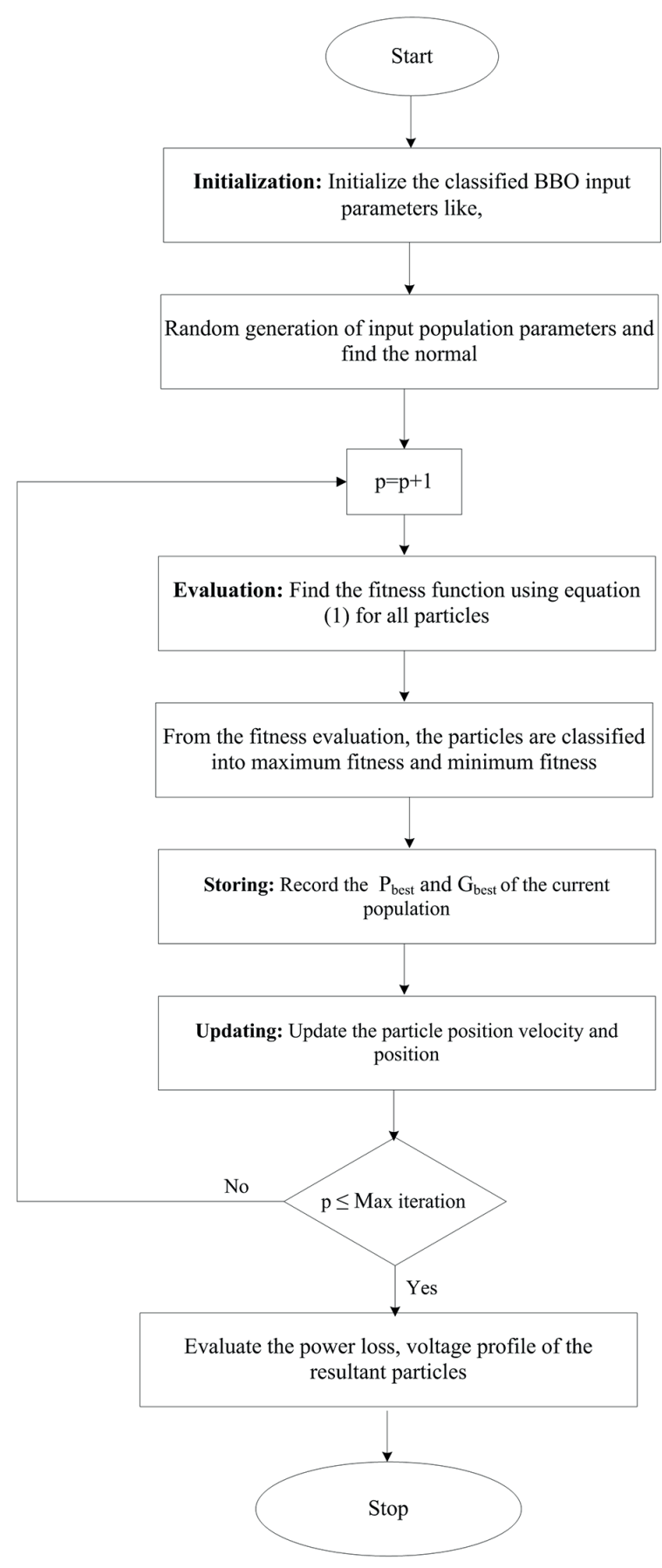

Fig. 3 PSO based optimization structure

distribution system the approval of the proposed method is portrayed in the accompanying Section 4.1.

\subsection{Validation of IEEE 33 bus distribution systems}

The proposed method validation is depicted in this segment. Here, the tested radial distribution system structure is shown in Fig. 4, in which the 33 nodes and 32 branches. In the p.u system the assessments are completed with the $12.66 \mathrm{kV}$ and 100MVA. The distribution system

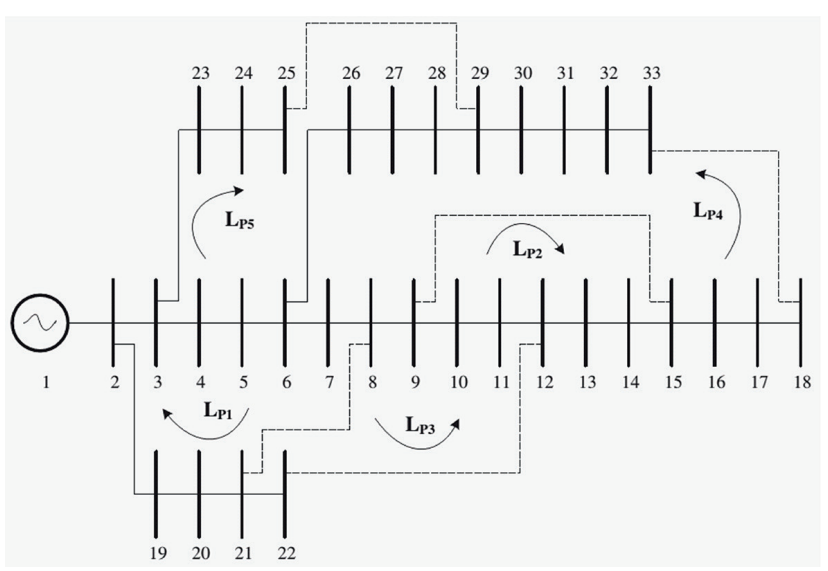

Fig. 4 IEEE 33 bus radial distribution system single line diagram

structure of IEEE 33 bus is depicted in the following Fig. 3. Here, by the proposed technique the IEEE 33 bus radial distribution system voltage, power loss evaluations are finished. The accompanying area determines the correlation investigation has used diverse sorts of cases.

Case 1: Without reconfiguration of the bus system and the DG units

Case 2: Optimally reconfigured system of bus by the accessible sectionalizing and tie switches

Case 3: DG unit's optimal size is introduced in the candidate bus.

Case 4: Optimally reconfigured bus system in nearness of optimal size of DG unit introduced at the candidate bus.

Under various load conditions and different cases Table 1 outlines the system voltage profile. In the subtitled Table 1, by strategies for the light (0.5), nominal (1) and heavy load (1.5) stipulations, type 1, type 2 and type 3 loads are addressed correspondingly. The scarcest voltage magnitude (p.u) is upgraded from $0.8955,0.8955$ and 0.8946 to $0.9965,0.9796$ and 0.9964 in the event that 4 , because of type 1, type 2 and type 3 loading conditions. Like the CALMS, LSA and ALO [11], Table 2 delineates the execution assessment of the proposed strategy opposite the present procedures. For this circumstance, by suitably picking DG sizes and reconfiguration for the entire scope of loading conditions, the novel approach tweaks the voltage profile of the IEEE 33 bus system. It is discovered that the slightest voltage overhauled by utilizing case 4 is the most outrageous, from among all the three loading conditions, which extends the matchless quality of the proposed procedure.

Figs. 5, 6 and 7 portray the voltage profile of the IEEE 33 standard benchmark framework for a few cases, for instance, light, nominal and the heavy load conditions 
Table 1 System voltage profile analysis using proposed method for different load levels

\begin{tabular}{|c|c|c|c|c|}
\hline \multirow{2}{*}{ Scenario } & \multirow{2}{*}{ Item } & \multicolumn{3}{|c|}{ Load type } \\
\hline & & Type 1 & Type 2 & Type 3 \\
\hline \multirow{4}{*}{ Case 1} & $\begin{array}{l}\text { Switches } \\
\text { opened }\end{array}$ & $\begin{array}{c}3-14-24- \\
27-30\end{array}$ & $\begin{array}{c}10-3-6- \\
21-15\end{array}$ & $\begin{array}{c}12-27-14- \\
6-9\end{array}$ \\
\hline & & 0.8955 (18) & $0.8955(18)$ & $0.8946(18)$ \\
\hline & (bus no) & Best 0.9965 & Best- 0.9963 & Best-0.9964 \\
\hline & $\begin{array}{l}V_{\text {best }} \\
\text { (bus no) }\end{array}$ & $0.9966(2)$ & $0.9966(2)$ & $0.9968(2)$ \\
\hline \multirow{3}{*}{ Case 2} & $\begin{array}{l}\text { Switches } \\
\text { opened }\end{array}$ & $2-13-8-32-18$ & $\begin{array}{c}12-12-10- \\
11-14\end{array}$ & $\begin{array}{c}18-17-16- \\
9-17\end{array}$ \\
\hline & $\begin{array}{l}V_{\text {worst }} \\
\text { (bus no) }\end{array}$ & $\begin{array}{c}0.8940(17) \\
\text { Best }-0.9971\end{array}$ & $\begin{array}{c}0.8947(17) \\
\text { Best- } 0.9963\end{array}$ & $0.8998(16)$ \\
\hline & $\begin{array}{l}V_{\text {best }} \\
\text { (bus no) }\end{array}$ & $0.9964(2)$ & 0.9969 (2) & $0.9964(2)$ \\
\hline \multirow{4}{*}{ Case 3} & $\begin{array}{l}\text { Switches } \\
\text { opened }\end{array}$ & $\begin{array}{c}3-14-24- \\
27-30\end{array}$ & $10-3-6-21-15$ & $12-27-14-6-9$ \\
\hline & $\begin{array}{l}V_{\text {worst }} \\
\text { (bus no) }\end{array}$ & 0.9251 (18) & $\begin{array}{c}0.9021(16) \\
\text { Best-0.9666 }\end{array}$ & $0.9023(32)$ \\
\hline & $\begin{array}{l}V_{\text {best }} \\
\text { (bus no) }\end{array}$ & 0.9964 (19) & $0.9966(2)$ & $0.9049(17)$ \\
\hline & $\begin{array}{l}\text { DG size } \\
\text { (bus no) }\end{array}$ & $50.3911(18)$ & $30.287(26)$ & $56.8484(6)$ \\
\hline \multirow{4}{*}{ Case 4} & $\begin{array}{l}\text { Switches } \\
\text { opened }\end{array}$ & $7-32-30-18-3$ & $\begin{array}{c}26-2-16- \\
22-17\end{array}$ & $31-31-6-17-17$ \\
\hline & $\begin{array}{l}V_{\text {worst }} \\
\text { (bus no) }\end{array}$ & $0.8970(17)$ & 0.8955 (18) & $0.9050(33)$ \\
\hline & $\begin{array}{l}V_{\text {best }} \\
\text { (bus no) }\end{array}$ & $0.9965(2)$ & $0.9796(3)$ & $0.9964(2)$ \\
\hline & $\begin{array}{l}\text { DG size } \\
\text { (bus no) }\end{array}$ & 99.769 (32) & $70.435(8)$ & $103.524(25)$ \\
\hline
\end{tabular}

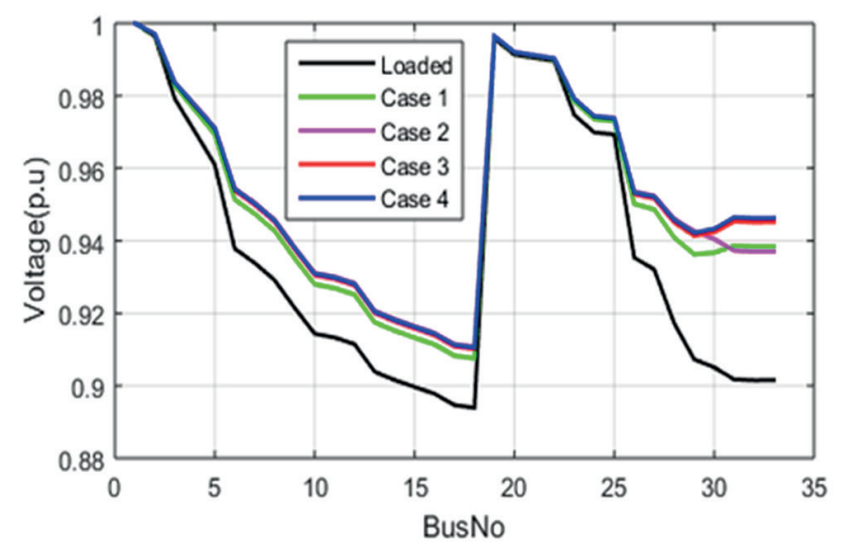

Fig. 5 Various cases voltage profile for type 1 load condition

utilizing the inventive system. At the point when the load blame harvests up, the standard voltage profile of the transport framework ends up plainly polluted. Here, by utilizing the reconfiguration of network, DG establishment and the perfect reconfiguration combined with the DG
Table 2 Voltage profile comparison for different type of load levels

\begin{tabular}{|c|c|c|c|c|c|}
\hline \multirow{2}{*}{ Scenario } & \multirow{2}{*}{ Item } & \multicolumn{4}{|c|}{ Solution techniques } \\
\hline & & Proposed & CALMS & LSA & ALO \\
\hline \multirow{4}{*}{ Type 1} & $\begin{array}{l}\text { Switches } \\
\text { opened }\end{array}$ & $\begin{array}{c}7-32-30- \\
18-3\end{array}$ & $\begin{array}{c}32-30-9- \\
11-25\end{array}$ & $\begin{array}{c}2-4-24- \\
27-10\end{array}$ & $\begin{array}{c}6-7-18- \\
23-10\end{array}$ \\
\hline & $\begin{array}{l}V_{\text {worst }} \\
\text { (bus no) }\end{array}$ & $\begin{array}{c}0.8970 \\
(17)\end{array}$ & $\begin{array}{c}0.9271 \\
(18)\end{array}$ & $\begin{array}{c}0.9131 \\
(18)\end{array}$ & $\begin{array}{c}0.8529 \\
(18)\end{array}$ \\
\hline & $\begin{array}{l}V_{\text {best }} \\
\text { (bus no) }\end{array}$ & $\begin{array}{l}0.9965 \\
(2)\end{array}$ & $\begin{array}{c}0.9965 \\
\text { (2) }\end{array}$ & $\begin{array}{c}0.9915 \\
(2)\end{array}$ & $\begin{array}{c}0.9885 \\
(2)\end{array}$ \\
\hline & $\begin{array}{l}\text { DG size } \\
\text { (bus no) }\end{array}$ & $\begin{array}{c}99.769 \\
(32)\end{array}$ & $\begin{array}{c}100.559 \\
(26)\end{array}$ & $\begin{array}{c}112.651 \\
(4)\end{array}$ & $\begin{array}{c}118.154 \\
(17)\end{array}$ \\
\hline \multirow{4}{*}{ Type 2} & $\begin{array}{l}\text { Switches } \\
\text { opened }\end{array}$ & $\begin{array}{c}26-2-16- \\
22-17\end{array}$ & $\begin{array}{c}27-32-23- \\
30-31\end{array}$ & $\begin{array}{c}3-4-10- \\
28-20\end{array}$ & $\begin{array}{l}16-14- \\
27-4-7\end{array}$ \\
\hline & $\begin{array}{l}V_{\text {worst }} \\
\text { (bus no) }\end{array}$ & $\begin{array}{c}0.8955 \\
(18)\end{array}$ & $\begin{array}{c}0.9145 \\
(17)\end{array}$ & $\begin{array}{c}0.9013 \\
(32)\end{array}$ & $\begin{array}{c}0.8952 \\
(32)\end{array}$ \\
\hline & $\begin{array}{l}V_{\text {best }} \\
\text { (bus no) }\end{array}$ & $\begin{array}{c}0.9796 \\
\text { (3) }\end{array}$ & $\begin{array}{c}0.9965 \\
(2)\end{array}$ & $\begin{array}{c}0.9875 \\
(2)\end{array}$ & $\begin{array}{c}0.9776 \\
(18)\end{array}$ \\
\hline & $\begin{array}{l}\text { DG size } \\
\text { (bus no) }\end{array}$ & $\begin{array}{c}70.435 \\
(8)\end{array}$ & $\begin{array}{c}96.399 \\
\text { (3) }\end{array}$ & $\begin{array}{c}105.365 \\
(6)\end{array}$ & $\begin{array}{c}116.987 \\
(4)\end{array}$ \\
\hline \multirow{4}{*}{ Type 3} & $\begin{array}{l}\text { Switches } \\
\text { opened }\end{array}$ & $\begin{array}{c}31-31-6- \\
17-17\end{array}$ & $\begin{array}{c}13-23-5- \\
6-9\end{array}$ & $\begin{array}{c}5-7-10- \\
18-9\end{array}$ & $\begin{array}{c}11-14-6- \\
21-17\end{array}$ \\
\hline & $\begin{array}{l}V_{\text {worst }} \\
\text { (bus no) }\end{array}$ & $\begin{array}{c}0.9050 \\
(33)\end{array}$ & $\begin{array}{c}0.9199 \\
(33)\end{array}$ & $\begin{array}{c}0.8988 \\
(17)\end{array}$ & $\begin{array}{c}0.8774 \\
(32)\end{array}$ \\
\hline & $\begin{array}{l}V_{\text {best }} \\
\text { (bus no) }\end{array}$ & $\begin{array}{c}0.9964 \\
(2)\end{array}$ & $\begin{array}{c}0.9975 \\
\text { (2) }\end{array}$ & $\begin{array}{c}0.9885 \\
(19)\end{array}$ & $\begin{array}{c}0.9801 \\
(2)\end{array}$ \\
\hline & $\begin{array}{l}\text { DG size } \\
\text { (bus no) }\end{array}$ & $\begin{array}{c}103.524 \\
(25)\end{array}$ & $\begin{array}{c}105.477 \\
(17)\end{array}$ & $\begin{array}{c}118.787 \\
(5)\end{array}$ & $\begin{array}{c}122.127 \\
(22)\end{array}$ \\
\hline
\end{tabular}

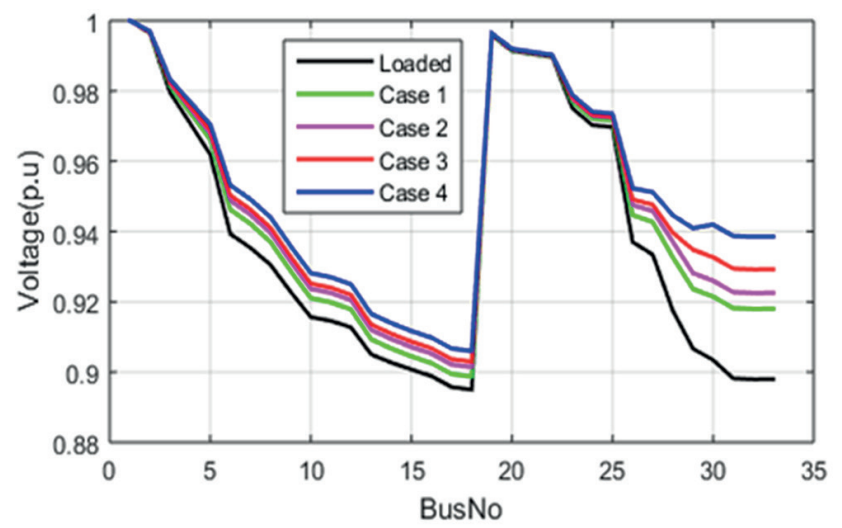

Fig. 6 Various cases voltage profile for type 2 load condition

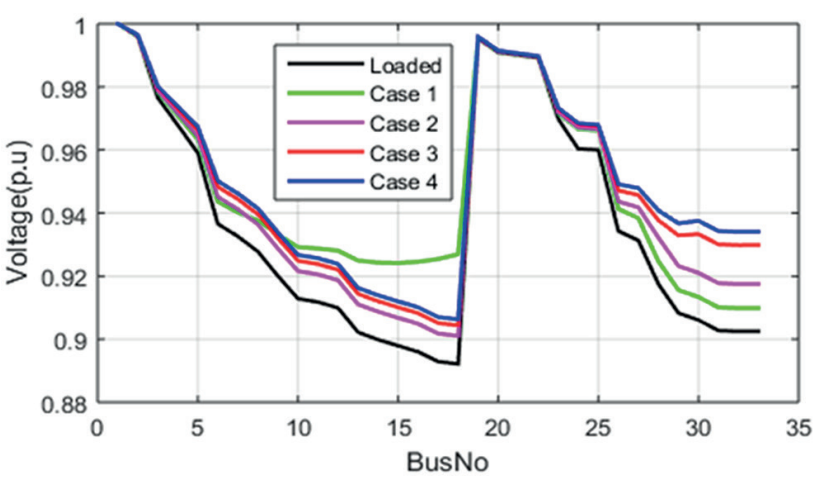

Fig. 7 Various cases voltage profile for type 3 load condition 
establishment the load addition is leveled. By and by, in a perfect world reconfiguring the system by setting up the ideal DG assess, the instrument voltage profile is reclaimed to the standard condition.

For the examination appraisal with the advanced methodologies, the proficiency of the age making strategy versus, the voltage profile is assessed. At all the loading conditions, the voltage profile for an ideal system reconfiguration with the DG set up is displayed in Figs. 8, 9 and 10 correspondingly.

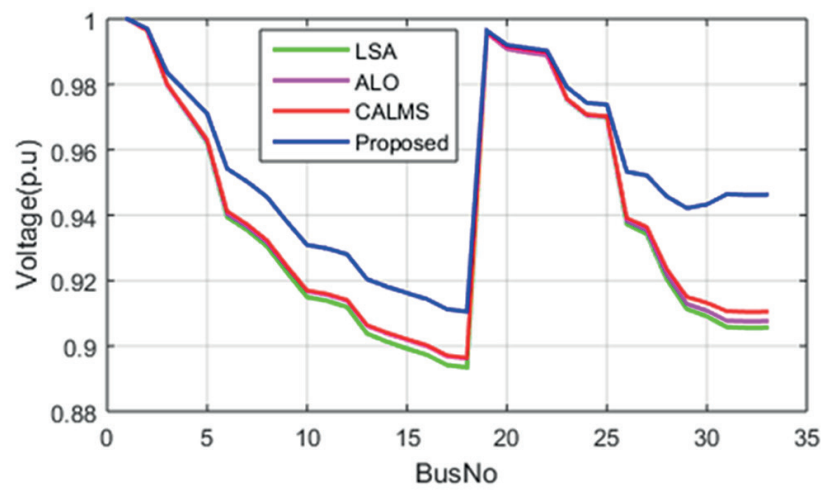

Fig. 8 Voltage profile comparison at type 1 load condition

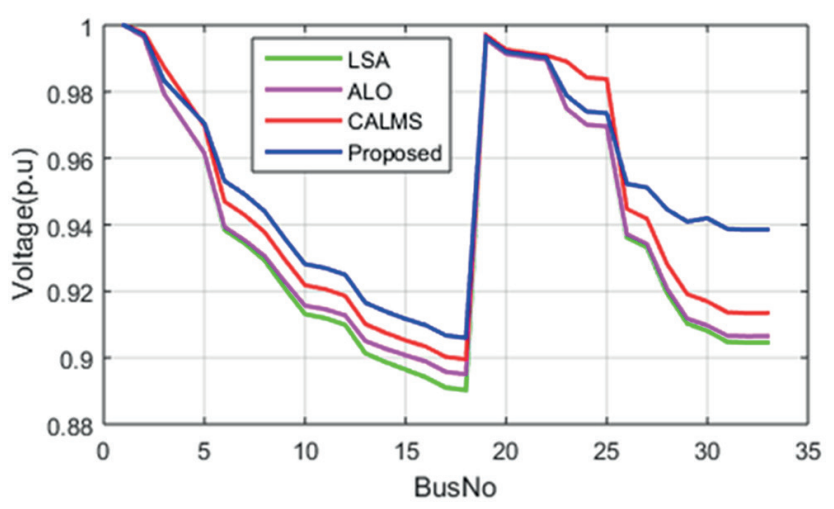

Fig. 9 Voltage profile comparison at type 2 load condition

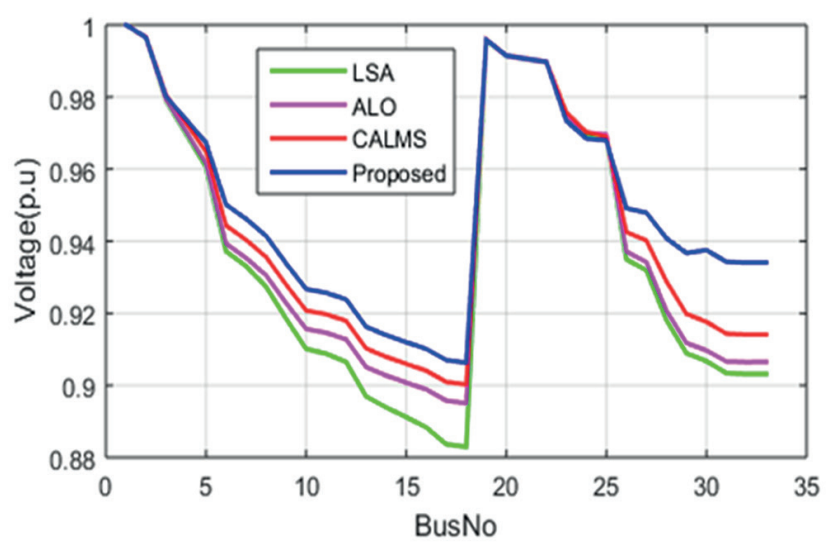

Fig. 10 Voltage profile comparison at type 3 load condition
In Table 3, it is obvious that by utilizing the case 2, case 3 and case 4, the base case power loss (KW) in the framework is 211, which is diminished to 146.12, 141.18 and 135.66 correspondingly (type 3 load condition). For cases 2 to 4 , the rate power loss reductions are 26.53, 28 and 31.14 correspondingly. The rate power loss lessening for cases 2 to 4 of every an indistinguishable way, on account of the light and substantial load conditions are 24.68, 26 and 34; 27.05, 30 and 31 correspondingly. Along these lines, with various strategies, for instance, the LSA and ALO, the power loss achieved by the inventive procedure for all the load conditions is surveyed. By diminishing loss to 138.97 as against the associate methodologies (LSA - 158.661; ALO - 174.801) at substantial load conditions it is discovered that the proposed technique has demonstrated its guts. In addition, in connection to other approaches at substantial load conditions, the level of power loss reduction in the age making approach is observed to be an incredible 24.68 (LSA - 24.81; ALO - 17.16). Table 4 shows the power loss comparison with different types of loads.

Table 3 System power loss analysis using proposed method for different load levels

\begin{tabular}{|c|c|c|c|c|}
\hline \multirow{2}{*}{ Scenario } & \multirow{2}{*}{ Item } & \multicolumn{3}{|c|}{ Load type } \\
\hline & & Type 1 & Type 2 & Type 3 \\
\hline \multirow{3}{*}{ Case 1} & $\begin{array}{l}\text { Switches } \\
\text { opened }\end{array}$ & $\begin{array}{c}3-14-24- \\
27-30\end{array}$ & $\begin{array}{c}10-3-6- \\
21-15\end{array}$ & $\begin{array}{c}12-27-14- \\
6-9\end{array}$ \\
\hline & Power loss & 210.31 & 211.25 & 216.09 \\
\hline & $\begin{array}{l}\text { Load fault } \\
\text { bus no. }\end{array}$ & 22 & 26 & 12 \\
\hline \multirow{4}{*}{ Case 2} & $\begin{array}{l}\text { Switches } \\
\text { opened }\end{array}$ & $2-13-8-32-18$ & $\begin{array}{c}12-12-10- \\
11-14\end{array}$ & $\begin{array}{c}18-17-16- \\
9-17\end{array}$ \\
\hline & Power loss & 138.97 & 145.56 & 146.12 \\
\hline & $\begin{array}{l}\text { Load fault } \\
\text { bus no. }\end{array}$ & 11 & 18 & 22 \\
\hline & $\begin{array}{l}\% \text { of loss } \\
\text { reduction }\end{array}$ & 24.68 & 27.05 & 26.53 \\
\hline \multirow{4}{*}{ Case 3} & Switch & $\begin{array}{c}3-14-24- \\
27-30\end{array}$ & $10-3-6-21-15$ & $12-27-14-6-9$ \\
\hline & Power loss & 132.24 & 138.14 & 141.18 \\
\hline & $\begin{array}{l}\text { Load fault } \\
\text { bus no. }\end{array}$ & 20 & 27 & 8 \\
\hline & $\begin{array}{l}\% \text { of loss } \\
\text { reduction }\end{array}$ & 26 & 30 & 28 \\
\hline \multirow{4}{*}{ Case 4} & Switch & $7-32-30-18-3$ & $\begin{array}{c}26-2-16- \\
22-17\end{array}$ & $\begin{array}{c}31-31-6- \\
17-17\end{array}$ \\
\hline & Power loss & 130.89 & 135.48 & 135.66 \\
\hline & $\begin{array}{l}\text { Load fault } \\
\text { bus no. }\end{array}$ & 30 & 10 & 28 \\
\hline & $\begin{array}{l}\% \text { of loss } \\
\text { reduction }\end{array}$ & 34 & 31 & 31.14 \\
\hline
\end{tabular}


Table 4 Power loss comparison for different type of load levels

\begin{tabular}{|c|c|c|c|c|c|}
\hline \multirow{2}{*}{ Scenario } & \multirow{2}{*}{ Item } & \multicolumn{4}{|c|}{ Solution techniques } \\
\hline & & Proposed & CALMS & LSA & ALO \\
\hline \multirow{4}{*}{ Type 1} & $\begin{array}{l}\text { Switches } \\
\text { opened }\end{array}$ & $\begin{array}{c}7-32-30- \\
18-3\end{array}$ & $\begin{array}{c}32-30-9- \\
11-25\end{array}$ & $\begin{array}{c}2-4-24- \\
27-10\end{array}$ & $\begin{array}{c}6-7-18- \\
23-10\end{array}$ \\
\hline & $\begin{array}{l}\text { Power } \\
\text { loss }\end{array}$ & 130.89 & 132.222 & 158.661 & 174.801 \\
\hline & Bus no. & 30 & 20 & 17 & 24 \\
\hline & $\begin{array}{l}\% \text { of loss } \\
\text { reduction }\end{array}$ & 34 & 37.34 & 24.81 & 17.16 \\
\hline \multirow{4}{*}{ Type 2} & Switch & $\begin{array}{c}26-2-16- \\
22-17\end{array}$ & $\begin{array}{c}27-32-23- \\
30-31\end{array}$ & $\begin{array}{c}3-4-10- \\
28-20\end{array}$ & $\begin{array}{l}16-14- \\
27-4-7\end{array}$ \\
\hline & $\begin{array}{l}\text { Power } \\
\text { loss }\end{array}$ & 135.48 & 140.910 & 161.965 & 165.632 \\
\hline & Bus no. & 10 & 11 & 22 & 18 \\
\hline & $\begin{array}{l}\% \text { of loss } \\
\text { reduction }\end{array}$ & 31 & 33.22 & 23.24 & 21.50 \\
\hline \multirow{4}{*}{ Type 3} & Switch & $\begin{array}{c}31-31-6- \\
17-17\end{array}$ & $\begin{array}{c}13-23-5- \\
6-9\end{array}$ & $\begin{array}{c}5-7-10- \\
18-9\end{array}$ & $\begin{array}{c}11-14-6- \\
21-17\end{array}$ \\
\hline & $\begin{array}{l}\text { Power } \\
\text { loss }\end{array}$ & 135.66 & 140.726 & 157.150 & 169.851 \\
\hline & Bus no. & 28 & 10 & 15 & 24 \\
\hline & $\begin{array}{l}\% \text { of loss } \\
\text { reduction }\end{array}$ & 31.14 & 33.31 & 25.52 & 19.50 \\
\hline
\end{tabular}

Figs. 11, 12 and 13 depict the power loss of the IEEE 33 outspread dispersion framework under light, medium and heavy load condition utilizing the inventive methodology correspondingly. To broadly diminishment the loss of the framework in connection to the parallel methodologies obviously the proposed technique is skillful.

In Figs. 14, 15 and 16, with various techniques under light, medium and overwhelming conditions of load the power loss brought about by the proposed strategy is estimated by methods for the perfect reconfiguration combined with DG establishment correspondingly. The proposed technique causes the minimum power loss opposite those of the parallel methodologies it is demonstrated without a particle of vulnerability.

Everything considered, in regard of all the contextual investigations, the improvement in rate of power loss diminishes and the minimum voltage greatness is observed be pretty much indistinguishable, at all the three loading conditions. The examination has revealed the way that in calibrating the voltage profile and chopping down the instrument power loss, the synchronous system reconfiguration and the assignment of DG in the applicant transport area goes far.

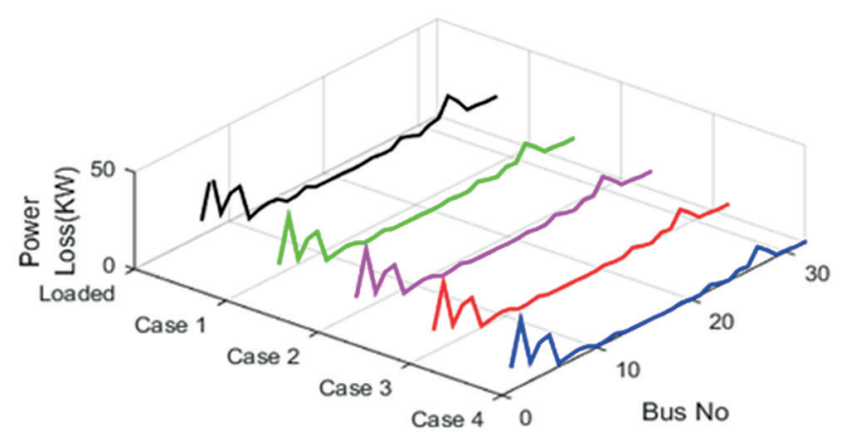

Fig. 12 Power loss comparison at type 2 load condition

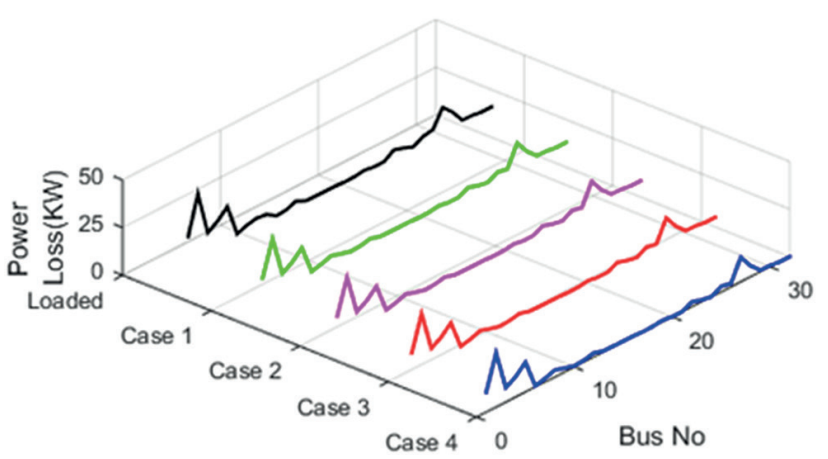

Fig. 11 Comparison of power loss at type 1 load condition

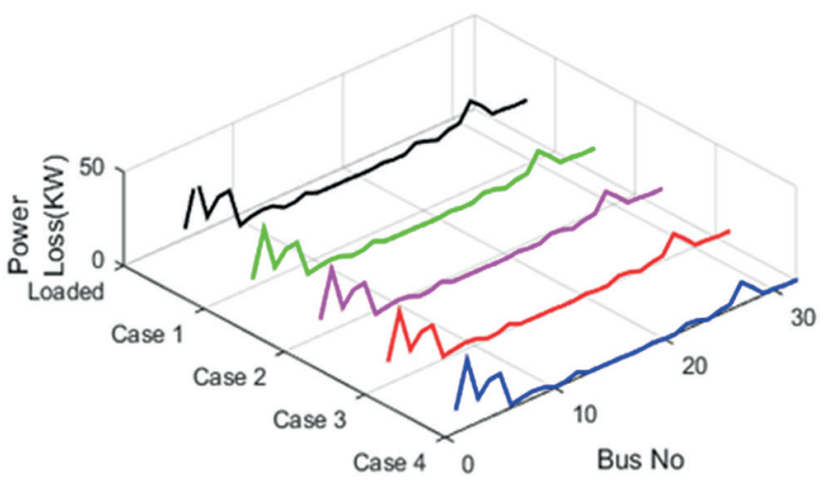

Fig. 13 Various cases power loss at type 3 load condition

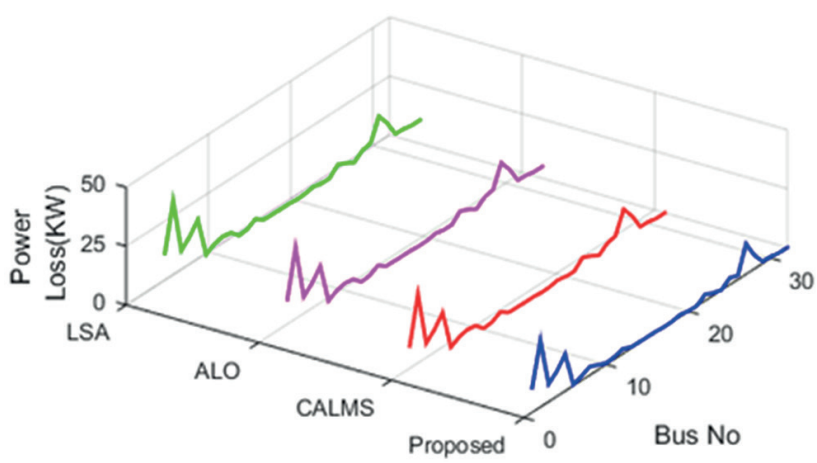

Fig. 14 Power loss for various cases at type 1 load condition 


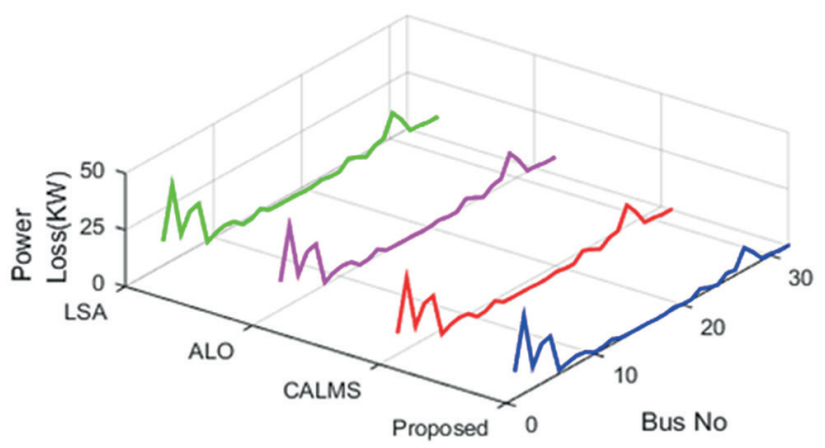

Fig. 15 Various cases power loss at type 2 load condition

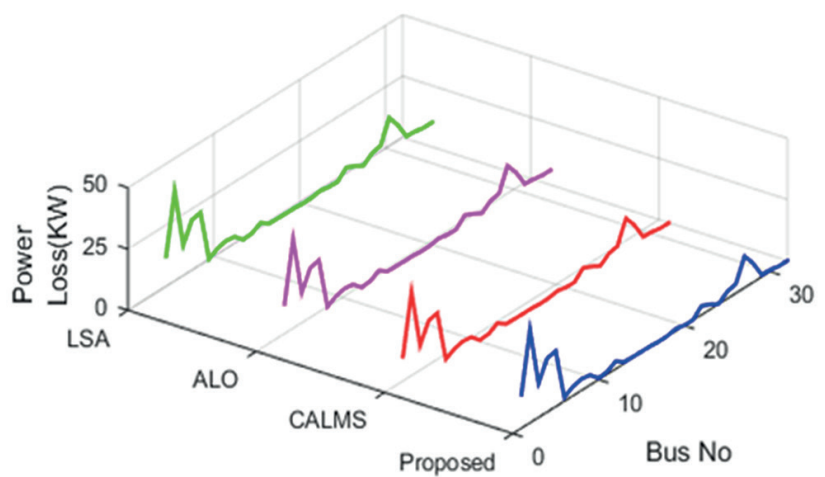

Fig. 16 Contrast of power loss at type 3 load condition

\section{References}

[1] Hung, D. Q., Mithulananthan, N., Bansal, R. C. "Analytical strategies for renewable distributed generation integration considering energy loss minimization", Applied Energy, 105, pp. 75-85, 2013. https://doi.org/10.1016/j.apenergy.2012.12.023

[2] Abdi, S., Afshar, K. "Application of IPSO-Monte Carlo for optimal distributed generation allocation and sizing", International Journal of Electrical Power and Energy Systems, 44(1), pp. 786-797, 2013. https://doi.org/10.1016/j.ijepes.2012.08.006

[3] Tan, W.-S., Hassann, M. Y., Majid, M. S., Rahman, H. A. "Optimal distributed renewable generation planning: A review of different approaches", Renewable and Sustainable Energy Reviews, 18, pp. 626-645, 2013.

https://doi.org/10.1016/j.rser.2012.10.039

[4] Borges, C. L. T., Falcão, D. M. "Optimal distributed generation allocation for reliability, losses, and voltage improvement", International Journal of Electrical Power and Energy Systems, 28(6), pp. 413-420, 2006.

https://doi.org/10.1016/j.ijepes.2006.02.003

[5] Prenc, R., Škrlec, D., Komen, V. "Distributed generation allocation based on average daily load and power production curves", International Journal of Electrical Power and Energy Systems, 53, pp. 612-622, 2013.

https://doi.org/10.1016/j.ijepes.2013.05.033

[6] Hernández, J. C., Ruiz-Rodriguez, F. J., Jurado, F. "Technical impact of photovoltaic-distributed generation on radial distribution systems: Stochastic simulations for a feeder in Spain", International Journal of Electrical Power and Energy Systems, 50, pp. 25-32, 2013. https://doi.org/10.1016/j.ijepes.2013.02.010

\section{Conclusion}

This paper demonstrates a mutual approach for locating the capacity of DG in power system. In the proposed method, by utilizing BBO the optimal location and capacity of the DG is first resolved, then the input parameters of $\mathrm{BBO}$ are categorized into the sub parameters and permitted as the input of PSO. The PSO utilizes the sub parameters to locate the optimum location and capacity of DG. Finally among these methods the best outcomes were taken. This process is tried in the IEEE 33 transport spiral dispersion framework and the effectiveness is scrutinized with the BBO algorithm. Here the difference takes the power loss of radial distribution system, voltage at various conditions like normal condition during the fault time in BBO technique and proposed mutual technique. From the examination results we clinched that the proposed strategy is the well compelling technique to recognize the optimum location and capacity of the DG for the radial distribution system, which is efficient over the alternate strategies.

[7] Devi, S., Geethanjali, M. "Application of Modified Bacterial Foraging Optimization algorithm for optimal placement and sizing of Distributed Generation", Expert Systems with Applications, 41(6), pp. 2772-2781, 2013.

https://doi.org/10.1016/j.eswa.2013.10.010

[8] Borges, C. L. T. "An overview of reliability models and methods for distribution systems with renewable energy distributed generation", Renewable and Sustainable Energy Reviews, 16(6), pp. 4008-4015, 2012.

https://doi.org/10.1016/j.rser.2012.03.055

[9] Viral, R., Khatod, D. K. "Optimal planning of distributed generation systems in distribution system: A review", Renewable and Sustainable Energy Reviews, 16(7), pp. 5146-5165, 2012. https://doi.org/10.1016/j.rser.2012.05.020

[10] Ugranl, F., Karatepe, E. "Multiple-distributed generation planning under load uncertainty and different penetration levels", International Journal of Electrical Power and Energy Systems, 46, pp. 132-144, 2013.

https://doi.org/10.1016/j.ijepes.2012.10.043

[11] El-Zonkoly, A. M. "Optimal placement of multi-distributed generation units including different load models using particle swarm optimization", Swarm and Evolutionary Computation, 1(1), pp. 50-59, 2011.

https://doi.org/10.1016/j.swevo.2011.02.003

[12] Junjie, M., Yulong, W., Yang, L. "Size and Location of Distributed Generation in Distribution System Based on Immune Algorithm", Systems Engineering Procedia, 4, pp. 124-132, 2012. https://doi.org/10.1016/j.sepro.2011.11.057 
[13] Rotaru, F., Chicco, G., Grigoras, G., Cartina, G. "Two-stage distributed generation optimal sizing with clustering-based node selection", International Journal of Electrical Power and Energy Systems, 40(1), pp. 120-129, 2012. https://doi.org/10.1016/j.ijepes.2012.02.012

[14] Ghosh, S., Ghoshal, S. P., Ghosh, S. "Optimal sizing and placement of distributed generation in a network system", International Journal of Electrical Power and Energy Systems, 32(8), pp. 849-856, 2010. https://doi.org/10.1016/j.ijepes.2010.01.029

[15] Rueda-Medina, A. C., Franco, J. F., Rider, M. J., PadilhaFeltrin, A., Romero, R. "A mixed-integer linear programming approach for optimal type, size and allocation of distributed generation in radial distribution systems", Electric Power Systems Research, 97, pp. 133-143, 2013. https://doi.org/10.1016/j.epsr.2012.12.009

[16] AlRashidi, M. R., AlHajri, M. F. "Optimal planning of multiple distributed generation sources in distribution networks: A new approach", Energy Conversion and Management, 52(11), pp. 3301-3308, 2011 https://doi.org/10.1016/j.enconman.2011.06.001

[17] de Souza, A. R. R., Fernandes, T. S. P., Aoki, A. R., Sans, M. R., Oening, A. P., Marcilio, D. C., Omori, J. S. "Sensitivity analysis to connect distributed generation", International Journal of Electrical Power and Energy Systems, 46, pp. 145-152, 2013. https://doi.org/10.1016/j.ijepes.2012.10.004

[18] Shahmohammadi, A., Ameli, M. T. "Proper sizing and placementv of distributed power generation aids the intentional islanding process", Electric Power Systems Research, 106, pp. 73-85, 2014. https://doi.org/10.1016/j.epsr.2013.08.005

[19] Kang, Q., Lan, T., Yan, Y., Wang, L., Wu, Q. "Group search optimizer based optimal location and capacity of distributed generations", Neurocomputing, 78(1), pp. 55-63, 2012. https://doi.org/10.1016/j.neucom.2011.05.030

[20] Andrés Martín García, J., José Gil Mena, A. "Optimal distributed generation location and size using a modified teaching-learning based optimization algorithm", International Journal of Electrical Power and Energy Systems, 50, pp. 65-75, 2013. https://doi.org/10.1016/j.ijepes.2013.02.023
[21] Kayal, P., Chanda, C. K. "Placement of wind and solar based DGs in distribution system for power loss minimization and voltage stability improvement", International Journal of Electrical Power and Energy Systems, 53, pp. 795-809, 2013. https://doi.org/10.1016/j.ijepes.2013.05.047

[22] Gopiya Naik, S., Khatod, D. K., Sharma, M. K. "Optimal allocation of combined DG and capacitor for real power loss minimization in distribution networks", International Journal of Electrical Power and Energy Systems, 53, pp. 967-973, 2013. https://doi.org/10.1016/j.ijepes.2013.06.008

[23] Esmaili, M., Firozjaee, E. C., Shayanfar, H. A. "Optimal placement of distributed generations considering voltage stability and power losses with observing voltage-related constraints", Applied Energy, 113, pp. 1252-1260, 2014. https://doi.org/10.1016/j.apenergy.2013.09.004

[24] Kansal, S., Kumar, V., Tyagi, B. "Optimal placement of different type of DG sources in distribution networks", International Journal of Electrical Power and Energy Systems, 53, pp. 752-760, 2013. https://doi.org/10.1016/j.ijepes.2013.05.040

[25] Moradi, M. H., Zeinalzadeh, A., Mohammadi, Y., Abedini, M. "An efficient hybrid method for solving the optimal sitting and sizing problem of DG and shunt capacitor banks simultaneously based on imperialist competitive algorithm and genetic algorithm", International Journal of Electrical Power and Energy Systems, 54, pp. 101-111, 2014. https://doi.org/10.1016/j.ijepes.2013.06.023

[26] Kashem, M. A., Ganapathy, V., Jasmon, G. B., Buhari, M. I. "A novel method for loss minimization in distribution networks", In: International Conference on Electric Utility Deregulation and Restructuring and Power Technologies, London, UK, 2000, pp. 251-256. https://doi.org/10.1109/DRPT.2000.855672

[27] Baran, M. E., Wu, F. F. "Optimal capacitor placement on radial distribution systems", IEEE Transactions on Power Delivery, 4(1), pp. $725-734,1989$. https://doi.org/10.1109/61.19265 